\title{
Ammonium Chloride
}

National Cancer Institute

\section{Source}

National Cancer Institute. Ammonium Chloride. NCI Thesaurus. Code C47396.

A systemic and urinary acidifying salt. Ammonium chloride helps maintain $\mathrm{pH}$ and exerts a mild diuretic effect. This acid forming salt also exerts an expectorant effect by irritating the mucous membranes and is used for alleviation of cough. 